BMJ Open

Diabetes

Research

\& Care

\title{
Feasibility of overnight closed-loop therapy in young children with type 1 diabetes aged 3-6 years: comparison between diluted and standard insulin strength
}

\author{
Daniela Elleri, ${ }^{1}$ Janet M Allen, ${ }^{1}$ Martin Tauschmann, ${ }^{1}$ Ranna El-Khairi, ${ }^{1}$ \\ Paul Benitez-Aguirre, ${ }^{1,2}$ Carlo L Acerini, ${ }^{1}$ David B Dunger, ${ }^{1}$ Roman Hovorka ${ }^{1}$
}

To cite: Elleri D, Allen JM, Tauschmann M, et al. Feasibility of overnight closed-loop therapy in young children with type 1 diabetes aged 3-6 years: comparison between diluted and standard insulin strength. BMJ Open Diabetes Research and Care 2014:2:e000040. doi:10.1136/bmjdrc-2014000040

- Additional material is available. To view please visit the journal (http://dx.doi.org/ 10.1136/bmjdrc-2014000040).

Received 23 May 2014 Revised 26 September 2014 Accepted 21 October 2014

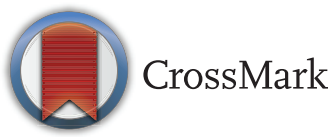

${ }^{1}$ Department of Paediatrics, Wellcome Trust-MRC Institute of Metabolic Science, University of Cambridge, Cambridge, UK ${ }^{2}$ Institute of Endocrinology and Diabetes, The Children's Hospital at Westmead, Sydney, Australia

Correspondence to Dr Roman Hovorka; rh347@cam.ac.uk

\section{ABSTRACT}

Objective: To assess feasibility of overnight closedloop therapy in young children with type 1 diabetes and contrast closed loop using diluted versus standard insulin strength.

Research design and methods: Eleven children (male 6; age range 3.75-6.96 years; glycated hemoglobin 60 (14) $\mathrm{mmol} / \mathrm{mol}$; body mass index SD score 1.0 (0.8); diabetes duration 2.2 (1.0) years, mean (SD); total daily dose $12.9(10.6,16.5)$ IU/day, median (IQR)) were studied at a clinical research facility on two occasions. In random order, participants received closed loop with diluted insulin aspart (CL_Dil; $20 \mathrm{IU} / \mathrm{mL}$ ) or closed loop with standard aspart (CL_Std; $100 \mathrm{IU} / \mathrm{mL}$ ) from 17:00 until 8:00 the following morning. Children consumed an evening meal at 17:00 (44 (12) gCHO) and an optional bedtime snack ( $6(7) \mathrm{gCHO}$ ) identical on both occasions. Meal insulin boluses were calculated by standard pump bolus calculators. Basal rates on insulin pump were adjusted every $15 \mathrm{~min}$ as directed by a model-predictive-control algorithm informed by a realtime glucose sensor values.

Results: Mean plasma glucose was 122 (24) mg/dL during CL_Dil vs 122 (23) $\mathrm{mg} / \mathrm{dL}$ during CL_Std $(p=0.993)$. The time spent in the target glucose range $70-145 \mathrm{mg} / \mathrm{dL}$ was $83(70,100) \%$ vs $72(54,81) \%$ ( $p=0.328)$. Time above $145 \mathrm{mg} / \mathrm{dL}$ was $13(0,27) \%$ vs $19(10,45) \%(p=0.477)$ and time spent below $70 \mathrm{mg} / \mathrm{dL}$ was $0.0(0.0,1.4) \%$ vs $1.4(0.0,11.6) \%(p=0.161)$. One asymptomatic hypoglycemia below $63 \mathrm{mg} / \mathrm{dL}$ occurred in one participant during $\mathrm{CL} \_$Dil versus six episodes in five participants during $\mathrm{CL}$ _Std $(p=0.09$ ). Glucose variability measured by $\mathrm{CV}$ of plasma glucose tended to be reduced during CL_Dil $(20 \%(13,31)$ vs $32 \%(24,42), p=0.075)$. Conclusions: In this feasibility study, closed-loop therapy maintained good overnight glucose control with tendency towards reduced hypoglycemia and reduced glucose variability using diluted insulin.

Trial registration number: clinicaltrials. gov Identifier: NCT01557634.

Closed-loop insulin delivery is an emerging medical innovation which aims to improve

\section{Key messages}

Closed-loop insulin delivery is a promising medical innovation for treatment of type 1 diabetes.

- Closed loop may be particularly beneficial for preschool children, who are more vulnerable to glycemic fluctuations and are at greater risk of hypoglycemia.

- Safe and efficacious overnight glucose control was attained during closed loop using diluted and standard insulin strength, with tendency to reduced hypoglycemia and glycemic variability with diluted insulin.

glycemic control while reducing the risk of hypoglycemia in type 1 diabetes. ${ }^{1}$ Closed-loop systems combine glucose-sensing and insulindelivery components to modulate delivery of insulin in a glucose-responsive fashion. The efficacy and safety of closed-loop therapy has been demonstrated in clinical studies performed in adolescents and children older than 6 years. $^{2-5}$ To date, one study evaluated closed-loop therapy in children younger than 7 years, using a proportional-integral-derivative control approach. ${ }^{6}$

Further closed-loop research in younger children is warranted. The incidence of type 1 diabetes is increasing particularly in this age group, ${ }^{7-9}$ younger children are more prone to hypoglycemic seizures especially overnight, ${ }^{10}$ and the developing brain appears to be more susceptible to the adverse effects of severe hypoglycemia. $^{11}$ A longer life-time exposure to hyperglycemia may lead to an accentuated risk of late microvascular and macrovascular complications. An early onset of diabetes has also been more strongly associated with impaired cognitive function ${ }^{12-15}$ and reduced school achievements, ${ }^{16}$ with recent evidence of 
dysglycemia-related anatomical brain changes in young children with type 1 diabetes. ${ }^{17}{ }^{18}$ Fear of hypoglycemia is common ${ }^{19}$ and is associated with increased psychological burden and reduced quality of life for children and their families, ${ }^{20}$ leading to higher than optimal glucose levels as an attempt to prevent hypoglycemia. ${ }^{21}{ }^{22}$ Glycemic control in preschool children is often suboptimal, even when applying continuous glucose monitoring combined with insulin pump or multiple daily injections. ${ }^{23}{ }^{24}$ High insulin sensitivity as well as unpredictable food intake and physical activity $^{25}$ complicate insulin dose adjustments. Infants and young children require very small doses of insulin that challenge the accuracy of subcutaneous insulin administration with standard concentration of $100 \mathrm{IU} / \mathrm{mL}^{26}$

The purpose of our feasibility study was to evaluate overnight closed-loop therapy with model predictive control in young children with type 1 diabetes and to compare closed loop using diluted versus standard insulin strength. We hypothesized that diluted insulin may lead to more stable glucose levels by reducing inaccuracies in insulin delivery accentuated during the delivery of small amounts of insulin. These inaccuracies result from electromechanical issues such as pump plunger microjumps, insulin reservoir manufacturing tolerances, in-line infusion set pressure variations, and infusion set kinking.

\section{RESEARCH DESIGN AND METHODS}

An open label randomized two-period crossover study compared overnight closed-loop insulin delivery using diluted versus standard insulin strength. The study was approved by the East of England-Cambridge Central Research Ethics Committee. Participants provided assent to the study procedures and informed consent was signed by a parent/carer.

\section{Subjects and study protocol}

The study was conducted at the Wellcome Trust Clinical Research Facility at Addenbrooke's Hospital, Cambridge, between December 2012 and November 2013. Children aged 3-6 years were recruited from three pediatric diabetes clinics at Cambridge, London University College Hospital, and Peterborough. Eligibility criteria included type 1 diabetes (WHO criteria) for at least 6 months, insulin pump therapy with good knowledge of insulin dose adjustment by carers, and glycated hemoglobin (HbAlc) below $108 \mathrm{mmol} / \mathrm{mol}(12 \%)$. Exclusion criteria were any physical or psychological disease likely to interfere with the normal conduct of the study and data interpretation or current treatment with drugs likely to interfere with glucose metabolism.

Participants attended the clinical research facility for two overnight periods, 2-6 weeks apart, with identical study protocol performed on both occasions. On one occasion, participants underwent closed-loop therapy using diluted insulin $(20 \mathrm{IU} / \mathrm{mL})$ and on the other occasion closed loop with standard insulin strength
$(100 \mathrm{IU} / \mathrm{mL})$. The order of the interventions was random according to a computer-generated allocation sequence with permuted blocks placed in sealed envelopes.

Continuous glucose monitoring was started $24-72 \mathrm{~h}$ before each study visit by inserting a single glucose sensor (Dexcom G4, Dexcom Inc, California, USA) into the subcutaneous tissue of the upper buttocks. Calibration followed manufacturer's instructions using finger-stick glucose measurements taken every $12 \mathrm{~h}$ on CONTOUR XT Meter (Bayer, Leverkusen, Germany) which was checked for accuracy by calibration fluid.

On each occasion, participants were admitted at 15:30 and stayed until 8:00 the following day. On admission, participant's insulin pump was replaced by a study pump (Animas 2020, Johnson \& Johnson, Pennsylvania, USA) connected to the existing infusion site. A new subcutaneous catheter was inserted 12-24 h before each study visit. An intravenous cannula was placed for blood sampling starting at 16:30. Participants consumed an evening meal at 17:00 (44 (12) g carbohydrates) and an optional bedtime snack (6 (7) g carbohydrates). The meals were identical on the two occasions. Meals and carbohydrate content were chosen by the children and their families based on individual preferences and reflecting usual practice at home. Meals were accompanied by insulin boluses calculated using participants' standard insulin pump bolus calculator settings and premeal finger-stick glucose levels.

Overnight sensor glucose levels were also recorded at home before each study visit while children maintained their usual exercise and eating patterns and standard insulin pump settings were applied.

\section{Closed loop and insulin dilution}

An algorithm based on model predictive control was used to adjust basal insulin delivery during both study visits. ${ }^{27}$ The operation of closed-loop therapy included manual transfer of sensor glucose data and adjustment of pump basal insulin infusion as advised by the computer-based algorithm at $15 \mathrm{~min}$ intervals, as described previously. ${ }^{5}$ This continued from 17:00 until 8:00 the next day for $15 \mathrm{~h}$.

The algorithm was initialized using participant's weight, total daily insulin dose, and basal insulin infusion. Additionally, the algorithm was provided with sensor glucose levels measured during a $30 \mathrm{~min}$ period preceding the start of closed-loop therapy, the carbohydrate content of meals, and prandial insulin boluses. No plasma glucose data were provided to the algorithm. Further details of the closed-loop algorithm are provided elsewhere $;{ }^{5}$ we used algorithm V.0.03.26.

During closed loop, rapid acting insulin analog aspart (Novo Nordisk, Bagsvaerd, Denmark) was infused either at standard strength $(100 \mathrm{IU} / \mathrm{mL})$ or diluted by $0.9 \%$ saline at $1: 5$ ratio resulting in an insulin concentration of $20 \mathrm{IU} / \mathrm{mL}$. 


\section{Sampling and assays}

Venous blood samples were obtained every 30-60 min for the measurement of glucose and insulin concentration. Plasma was separated by centrifugation immediately. Plasma glucose levels were determined in real time by YSI2300 STAT Plus analyzer (Yellow Springs Instrument, Farnborough, UK) but were not used to inform the algorithm. Plasma insulin concentration was measured by immunochemiluminometric assay (Invitron, Monmouth, UK; intra-assay coefficient of variation (CV), 4.7\%; interassay CV, 7.2-8.1\%).

\section{Statistical analysis}

The primary outcome was the time with plasma glucose levels within the target range from 70 to $145 \mathrm{mg} / \mathrm{dL}$ in the overnight period from 21:00 until 8:00 on the following day. Secondary outcomes included time when glucose concentration was below $70 \mathrm{mg} / \mathrm{dL}$ (hypoglycemia) and glucose variability as measured by the SD of glucose, the CV of glucose, and mean amplitude of glucose excursions (MAGE) ${ }^{28}$ Safety measures included hypoglycemia events (plasma glucose below $63 \mathrm{mg} / \mathrm{dL}$ ) and the low blood glucose index. ${ }^{29}$ Overnight sensor glucose levels collected at home before study visits were compared with sensor glucose levels measured during closed-loop insulin delivery between 21:00 and 8:00.

Outcomes were calculated using time-weighted data by GStat software, V.2.0 (University of Cambridge, UK). Statistical analyses were conducted using SPSS V.21 (IBM SPSS, Chicago, Illinois, USA). Wilcoxon signed-rank test was used to compare non-normally distributed indices and paired t test to compare normally distributed data. Results are presented as median (IQR) or mean (SD) unless stated otherwise. $p$ values less than 0.05 were considered statistically significant.

\section{RESULTS \\ Participants}

Fourteen participants were consented and randomized. Three participants withdrew after randomization, one at the start of the first study visit and two at the start of the second visit, due to failed attempts to establish intravenous sampling cannula. The study flow chart is shown in online supplementary figure S1. Eleven participants completed the study ((male 6; age 5.07 (1.12), range 3.75-6.96 years; HbA1c 60 (14) $\mathrm{mmol} / \mathrm{mol}$; body mass index SD score $1.0(0.8)$, range $-0.55,2.11$; duration of diabetes 2.2 (1.0) years; total daily dose $12.9(10.6,16.5)$ $\mathrm{IU} /$ day and $0.65(0.59,0.69) \mathrm{IU} / \mathrm{kg} /$ day $)$.

\section{Overnight glucose control}

Study outcomes during the overnight period are summarized in table 1. Plasma glucose, insulin delivery and plasma insulin during closed loop with standard insulin strength and closed loop with diluted insulin are shown in figure 1.

Plasma glucose levels remained within the target range of $70-145 \mathrm{mg} / \mathrm{dL}$ for $72 \%$ and $83 \%$ of the time, respectively, when closed loop with standard insulin strength and closed loop with diluted insulin was applied ( $p=0.328$; table 1 ). No difference was found in the mean plasma glucose concentration $(122$ (23) vs 122 (24) $\mathrm{mg} / \mathrm{dL}, \mathrm{p}=0.993$ ). A trend towards reduced time spent in hypoglycemia was observed during closed loop with diluted insulin (plasma glucose less than

Table 1 Study outcomes

\begin{tabular}{|c|c|c|c|}
\hline Outcome & $\begin{array}{l}\text { Closed loop with } \\
\text { standard insulin }(n=11)\end{array}$ & $\begin{array}{l}\text { Closed loop with } \\
\text { diluted insulin }(n=11)\end{array}$ & p Value \\
\hline \multicolumn{4}{|l|}{ Primary outcome } \\
\hline Time in target $70-145 \mathrm{mg} / \mathrm{dL}(\%)$ & $72(54,81)$ & $83(70,100)$ & 0.328 \\
\hline \multicolumn{4}{|l|}{ Secondary outcomes } \\
\hline Mean glucose $(\mathrm{mg} / \mathrm{dL})$ & $122(23)$ & $122(24)$ & 0.993 \\
\hline Time in target $70-180 \mathrm{mg} / \mathrm{dL}(\%)$ & $85(72,97)$ & $98(79,100)$ & 0.328 \\
\hline \multicolumn{4}{|l|}{ Hypoglycemia } \\
\hline Less than $70 \mathrm{mg} / \mathrm{dL}(\%)$ & $1.4(0.0,11.6)$ & $0.0(0.0,1.4)$ & 0.161 \\
\hline Less than $63 \mathrm{mg} / \mathrm{dL}(\%)$ & $0.0(0.0,7.9)$ & $0.0(0.0,0.0)$ & 0.249 \\
\hline Low blood glucose index (unitless) & $2.0(0.6,2.2)$ & $0.7(0.2,1.0)$ & 0.050 \\
\hline \multicolumn{4}{|l|}{ Hyperglycemia } \\
\hline Greater than 145 mg/dL (\%) & $18.8(9.5,44.9)$ & $13.0(0.0,26.9)$ & 0.477 \\
\hline Greater than 180 mg/dL (\%) & $5.1(0.0,26.8)$ & $0.0(0.0,15.3)$ & 0.953 \\
\hline \multicolumn{4}{|l|}{ Glucose variability } \\
\hline SD of glucose (mg/dL) & $35(26,53)$ & $26(14,39)$ & 0.091 \\
\hline CV of glucose (\%) & $32(24,42)$ & $20(13,31)$ & 0.075 \\
\hline MAGE (mg/dL) & $80(0,112)$ & $32(0,63)$ & 0.074 \\
\hline Insulin infusion (U/h) & $0.2(0.2,0.3)$ & $0.2(0.1,0.3)$ & 0.328 \\
\hline Insulin concentration (pmol/L) & $141(35,262)$ & $112(50,144)$ & 0.213 \\
\hline
\end{tabular}



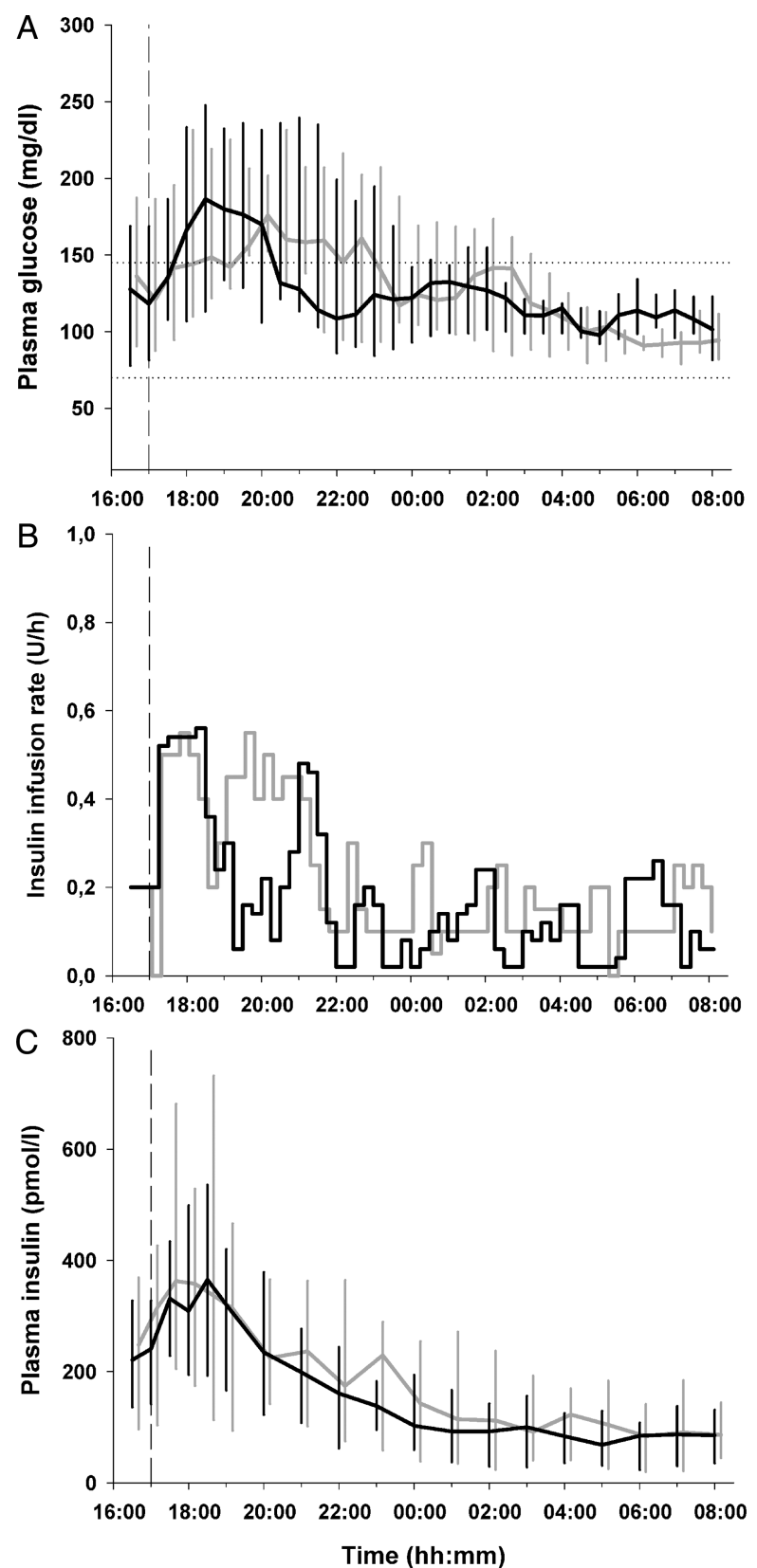

Figure 1 Plasma glucose $(A)$, insulin infusion rates $(B)$, and plasma insulin (C) are shown for closed loop with standard insulin strength (grey line) and closed loop with diluted insulin (black line; median (IQR)). Horizontal dashed lines illustrate the target glucose levels between 70 and $145 \mathrm{mg} / \mathrm{dL}$. The vertical dashed line indicates when closed loop started and the evening meal was consumed.

$70 \mathrm{mg} / \mathrm{dL}, \mathrm{p}=0.161)$. A reduced low blood glucose index supported this observation $(\mathrm{p}=0.050)$. Sensor-based assessment indicated significant reduction of time below $63 \mathrm{mg} / \mathrm{dL}(\mathrm{p}=0.028)$ and a reduced low blood glucose index ( $p=0.026$; see online supplementary table $\mathrm{S} 1)$.

Insulin infusion rates were not different during the two interventions $(0.2(0.2,0.3)$ vs $0.2(0.1,0.3) \mathrm{U} / \mathrm{h}$, $\mathrm{p}=0.328)$ and resulted in similar plasma insulin levels $(\mathrm{p}=0.213)$.

\section{Hypoglycemia and glucose variability}

No episode of hypoglycemia requiring treatment occurred during either intervention. One asymptomatic episode of hypoglycemia below $63 \mathrm{mg} / \mathrm{dL}$ as measured by plasma glucose occurred in one participant during closed loop with diluted insulin as compared with six episodes in five participants during closed loop with standard insulin $(\mathrm{p}=0.09)$. All these episodes resolved with no carbohydrate intake within 15-45 min.

All measurements of glycemic variability showed a tendency towards reduced variability during closed loop with diluted insulin, although these differences were not statistically significant (table 1).

\section{Sensor accuracy}

The median relative absolute difference of Dexcom G4 continuous glucose monitor was $11.6 \%(6.6,18.8)$. The Clarke error grid analysis ${ }^{30}$ (see online supplementary figure S2) provided $98.6 \%$ of the values were in zone $\mathrm{A}+\mathrm{B}, 0 \%$ in zone $\mathrm{C}, 1.4 \%$ in zone $\mathrm{D}$, and $0 \%$ in zone $\mathrm{E}$.

\section{Glycemic control at home}

Comparison between sensor glucose during conventional insulin pump therapy at home settings and closed-loop therapy using standard and diluted insulin is summarized in table 2.

\section{CONCLUSIONS}

We show that closed-loop therapy using a model predictive control approach can be safely and effectively applied for overnight glucose control in young children aged 3-6 years with type 1 diabetes. Plasma glucose levels were maintained between 70 and $145 \mathrm{mg} / \mathrm{dL}$ for $72 \%$ and $83 \%$ of the time using closed loop with standard and diluted insulin, respectively, and mean glucose was $122 \mathrm{mg} / \mathrm{dL}$ during both interventions. No episodes of hypoglycemia requiring treatment occurred over 22 study nights.

The present study builds on previous observations in older children and adolescents about benefits of overnight closed-loop therapy using the model predictive control at the clinical research facility ${ }^{5}$ and in the unsupervised home settings. ${ }^{31}$ In the present study, we document good glucose control in younger children, who may greatly benefit from closed-loop therapy. Similar results in terms of proportion of time spent in the target range and in hypoglycemia were obtained in this age group as compared with older children and adolescents. ${ }^{32} 33$ The daily management of diabetes in a young child is complicated by amplified responsiveness to insulin, increased risk of nocturnal hypoglycemia, high glucose variability and unpredictability of food intake and physical activity. While the avoidance of hypoglycemia is a crucial concern, chronic hyperglycemia and glucose variability have been suggested to be equally detrimental for brain development and may affect cognition. ${ }^{18}$ Children younger than 4 years were 
Table 2 Comparison between glucose control based on sensor glucose during standard insulin pump therapy at home the night before the study visits and during closed loop with diluted and standard insulin at the clinical research facility

\begin{tabular}{|c|c|c|c|}
\hline Outcome & $\begin{array}{l}\text { Insulin pump } \\
\text { therapy at home }(n=11)\end{array}$ & $\begin{array}{l}\text { Closed loop with } \\
\text { standard insulin }(n=11)\end{array}$ & $\begin{array}{l}\text { Closed loop with } \\
\text { diluted insulin }(n=11)\end{array}$ \\
\hline \multicolumn{4}{|l|}{ Primary outcome } \\
\hline Time in target $70-145 \mathrm{mg} / \mathrm{dL}(\%)$ & $32(30,59)$ & $71(51,78)$ & $78(68,94)$ \\
\hline \multicolumn{4}{|l|}{ Secondary outcomes } \\
\hline Mean glucose $(\mathrm{mg} / \mathrm{dL})$ & $151(71)$ & $126(30)$ & $121(22)$ \\
\hline Time in target $70-180 \mathrm{mg} / \mathrm{dL}(\%)$ & $59(44,76)$ & $82(61,91)$ & $89(77,95)$ \\
\hline \multicolumn{4}{|l|}{ Hypoglycemia } \\
\hline Less than $70 \mathrm{mg} / \mathrm{dL}(\%)$ & $12(0,23)$ & $8.0(2.4,17.7)$ & $1.8(0.0,4.8)$ \\
\hline Less than $63 \mathrm{mg} / \mathrm{dL}(\%)$ & $4.7(0.0,11.6)$ & $4.1(0.8,11.4)$ & $0.0(0.0,0.0)$ \\
\hline Low blood glucose index (unitless) & $1.7(0.1,5.4)$ & $1.7(1.2,3.3)$ & $1.0(0.7,1.4)$ \\
\hline \multicolumn{4}{|l|}{ Hyperglycemia } \\
\hline Greater than 145 mg/dL (\%) & $52(15,69)$ & $15(12,32)$ & $17(2,32)$ \\
\hline Greater than $180 \mathrm{mg} / \mathrm{dL}$ (\%) & $22(4,35)$ & $2(0,21)$ & $9(0,17)$ \\
\hline \multicolumn{4}{|l|}{ Glucose variability } \\
\hline SD of glucose $(\mathrm{mg} / \mathrm{dL})$ & $42(30,51)$ & $33(27,57)$ & $35(18,44)$ \\
\hline CV of glucose (\%) & $27(23,44)$ & $32(27,46)$ & $30(17,34)$ \\
\hline MAGE (mg/dL) & $67(41,107)$ & $100(56,141)$ & $77(26,102)$ \\
\hline Insulin infusion $(\mathrm{U} / \mathrm{h})$ & $0.2(0.1,0.2)$ & $0.2(0.2,0.3)$ & $0.2(0.1,0.3)$ \\
\hline
\end{tabular}

found to spend more than $4 \mathrm{~h} /$ day with glucose levels greater than $250 \mathrm{mg} / \mathrm{dL}$ when continuous glucose monitoring was applied. ${ }^{25}$ Similarly, no evidence of improved glycemic control with insulin pump therapy has been demonstrated in younger children ${ }^{34}$ possibly owing to the small number of studies targeting this age group.

Closed-loop insulin delivery using a proportional-integralderivative approach in children younger than 7 years was investigated by Dauber et at documenting reduced overnight exposure to hyperglycemia as compared with conventional insulin pump therapy. Although closed loop was not associated with improvements in the time spent in target or with reduced frequency of hypoglycemia, the study was the first to evaluate closed-loop therapy in younger children.

The novelty of our study is the use of diluted insulin to enhance the accuracy of delivery of small insulin doses. When compared with standard insulin strength, diluted insulin during closed-loop therapy tended to reduce the risk of hypoglycemia as evaluated by the low blood glucose index $(p=0.050)$ and time spent in hypoglycemia less than $70 \mathrm{mg} / \mathrm{dL} \quad(\mathrm{p}=0.161)$. Sensor-based assessment of hypoglycemia showed a significant reduction in the time spent in hypoglycemia below $63 \mathrm{mg} / \mathrm{dL}$ $(p=0.028)$ and the low blood glucose index $(p=0.026)$ suggesting that sensor errors attenuated the differences when outcomes were measured by reference plasma glucose. ${ }^{35}$ Sensor accuracy data are sparse in this young age group. Episodes of asymptomatic self-resolving mild hypoglycemia tended to be lower during closed loop using diluted insulin $(\mathrm{p}=0.09)$.

We observed a tendency towards reduced glycemic variability during closed loop with diluted insulin. The median CV of glucose was 20\% during closed loop with diluted insulin versus $32 \%$ when standard strength insulin was used $(p=0.075)$. Other measures of glucose variability confirmed this trend (table 1 ). These CVs are lower than those reported by Tsalikian et $a l^{23}$ who observed a median CV of glucose between $35 \%$ and $45 \%$ in children younger than 4 years using continuous glucose monitoring, and by Slover $e t a l^{36}$ during sensoraugmented pump therapy. Glycemic variability has been inconsistently associated with the risk of vascular complications in diabetes. ${ }^{37}$ In younger children, increased glycemic variability along with chronic exposure to hyperglycemia have been recently found to be associated with changes in the brain's white matter. ${ }^{17}$

We chose a dilution so that the volume of insulin scales from $10 \mathrm{U} /$ day of standard strength insulin to $50 \mathrm{U} /$ day of diluted insulin, a common amount applicable in adults. The latter converts to basal insulin delivery of about $1 \mathrm{U} / \mathrm{h}$, a rate at which accuracy of insulin pump is assessed and optimized. A greater dilution may further increase accuracy by limiting the effect of microbubbles and to overcome tissue pressure build-up but greater dilutions may be an issue in children requiring a larger amount of insulin due to pain at the cannula site.

The strength of the study is the randomized study design. The lack of control therapy is a limitation motivated by practical reasons to reduce burden for young participants and taking into account existing evidence of suboptimal glycemic control with frequent hyperglycemic excursions $^{2324}$ and undetected hypoglycemia ${ }^{38}$ in younger children on standard therapy. We carried out a post hoc analysis and although detailed information on 
children's schedule at home, that is, the time of evening meal/bedtime the night before the study was not available, our data showed that glucose control during conventional pump therapy in the home settings appeared inferior to that obtained during closed-loop therapy using standard as well as diluted insulin (table 2).

In conclusion, the present exploratory study suggests that closed-loop insulin delivery using the model predictive control approach is safe and efficacious to maintain overnight glycemic control in young children with type 1 diabetes. Closed-loop therapy using insulin dilution tended to reduce hypoglycemia and glycemic variability as compared to closed loop with standard insulin strength. The use of insulin dilution to enhance accuracy of insulin delivery may be explored in larger studies. Difficulties related to the use of insulin dilution, that is, the need to prepare diluted insulin every 7-14 days and the availability of specific software on insulin pumps to avoid dosing errors, may also need to be taken into account. Our findings support research into closed-loop therapy in preschool children, who may greatly benefit from this novel therapeutic approach.

Acknowledgements The authors are grateful to the study volunteers for their participation and to staff at the Wellcome Trust Clinical Research Facility for their help in conducting the studies. Dr Vijith Puthi (Peterborough Hospital) and Professor Peter Hindmarsh (University College, London) helped identifying potential recruits. Animas supplied study pumps. Josephine Hayes (Institute of Metabolic Science, University of Cambridge) provided administrative support. Karen Whitehead (Department of Paediatrics, University of Cambridge) provided laboratory support. The Diabetes Research Network Laboratory Wales (Dr Steve Luzio) measured plasma insulin.

Contributors DE, MT, and RH had full access to all of the data in the study and take responsibility for the integrity of the data and the accuracy of the data analysis. RH coordinated the study. DE, RH, DBD, CLA, and JMA co-designed the studies. DE, JMA, RE-K, PB-A, and MT were responsible for screening and enrolment of participants and arranged informed consent from the participants, provided patient care, collected the clinical and laboratory data, and contributed to biochemical analysis. DE, MT, and RH carried out or supported the data analysis, including the statistical analyses. $\mathrm{RH}$ designed and implemented the glucose controller. RH, DBD, DE, MT, and CLA contributed to the interpretation of the results and the writing and critical review of the report.

Funding This work was funded by the Juvenile Diabetes Research Foundation (JDRF Grant Number: 22-2011-668) and supported by NIHR Cambridge Biomedical Research Centre.

Competing interests $\mathrm{RH}$ reports having received speaker honoraria from Minimed Medtronic, Lifescan, Eli Lilly, and Novo Nordisk, serving on advisory panel for Animas and Minimed Medtronic, receiving license fees from BBraun and Beckton Dickinson; and having served as a consultant to Beckton Dickinson, BBraun and Profil. RH and DBD report patent applications.

\section{Patient consent Obtained.}

Ethics approval East of England-Cambridge Central Research Ethics Committee.

\section{Provenance and peer review Not commissioned; externally peer reviewed.}

Open Access This is an Open Access article distributed in accordance with the Creative Commons Attribution Non Commercial (CC BY-NC 4.0) license, which permits others to distribute, remix, adapt, build upon this work noncommercially, and license their derivative works on different terms, provided the original work is properly cited and the use is non-commercial. See: http:// creativecommons.org/licenses/by-nc/4.0/

\section{REFERENCES}

1. Elleri D, Dunger DB, Hovorka R. Closed-loop insulin delivery for treatment of type 1 diabetes. BMC Med 2011;9:120.

2. Phillip M, Battelino T, Atlas E, et al. Nocturnal glucose control with an artificial pancreas at a diabetes camp. $N$ Engl J Med 2013;368:824-33

3. Weinzimer SA, Steil GM, Swan KL, et al. Fully automated closed-loop insulin delivery versus semiautomated hybrid control in pediatric patients with type 1 diabetes using an artificial pancreas. Diabetes Care 2008;31:934-9.

4. Elleri D, Allen JM, Kumareswaran K, et al. Closed-loop basal insulin delivery over 36 hours in adolescents with type 1 diabetes: randomized clinical trial. Diabetes Care 2013;36:838-44.

5. Hovorka R, Allen JM, Elleri D, et al. Manual closed-loop insulin delivery in children and adolescents with type 1 diabetes: a phase 2 randomised crossover trial. Lancet 2010;375:743-51.

6. Dauber A, Corcia L, Safer J, et al. Closed-loop insulin therapy improves glycemic control in children aged $<7$ years: a randomized controlled trial. Diabetes Care 2013;36:222-7.

7. Hummel K, McFann KK, Realsen J, et al. The increasing onset of type 1 diabetes in children. J Pediatr 2012;161:652-7.

8. Patterson CC, Dahlquist GG, Gyurus E, et al. Incidence trends for childhood type 1 diabetes in Europe during 1989-2003 and predicted new cases 2005-20: a multicentre prospective registration study. Lancet 2009;373:2027-33.

9. DIAMOND Project Group. Incidence and trends of childhood Type 1 diabetes worldwide 1990-1999. Diabet Med 2006;23:857-66.

10. Davis EA, Keating B, Byrne GC, et al. Hypoglycemia: incidence and clinical predictors in a large population-based sample of children and adolescents with IDDM. Diabetes Care 1997;20:22-5.

11. Kaufman FR, Epport K, Engilman R, et al. Neurocognitive functioning in children diagnosed with diabetes before age 10 years. $J$ Diabetes Complications 1999;13:31-8

12. Gaudieri PA, Chen R, Greer TF, et al. Cognitive function in children with type 1 diabetes: a meta-analysis. Diabetes Care 2008;31:1892-7.

13. Ryan CM. Why is cognitive dysfunction associated with the development of diabetes early in life? The diathesis hypothesis. Pediatr Diabetes 2006;7:289-97.

14. Ferguson SC, Blane A, Wardlaw J, et al. Influence of an early-onset age of type 1 diabetes on cerebral structure and cognitive function. Diabetes Care 2005;28:1431-7.

15. Schoenle EJ, Schoenle D, Molinari L, et al. Impaired intellectual development in children with type I diabetes: association with $\mathrm{HbA}(1 \mathrm{c})$, age at diagnosis and sex. Diabetologia 2002;45:108-14.

16. Persson S, Dahlquist G, Gerdtham UG, et al. Impact of childhood-onset type 1 diabetes on schooling: a population-based register study. Diabetologia 2013;56:1254-62.

17. Barnea-Goraly N, Raman M, Mazaika P, et al. Alterations in white matter structure in young children with type 1 diabetes. Diabetes Care 2014;37:332-40.

18. Marzelli MJ, Mazaika PK, Barnea-Goraly N, et al. Neuroanatomical correlates of dysglycemia in young children with type 1 diabetes. Diabetes 2014;63:343-53.

19. Barnard K, Thomas S, Royle P, et al. Fear of hypoglycaemia in parents of young children with type 1 diabetes: a systematic review. BMC Pediatr 2010;10:50.

20. Johnson SR, Cooper MN, Davis EA, et al. Hypoglycaemia, fear of hypoglycaemia and quality of life in children with Type 1 diabetes and their parents. Diabet Med 2013;30:1126-31.

21. Patton SR, Dolan LM, Henry R, et al. Parental fear of hypoglycemia: young children treated with continuous subcutaneous insulin infusion. Pediatr Diabetes 2007;8:362-8.

22. Tupola S, Rajantie J, Akerblom HK. Experience of severe hypoglycaemia may influence both patient's and physician's subsequent treatment policy of insulin-dependent diabetes mellitus. Eur J Pediatr 1998;157:625-7.

23. Tsalikian E, Fox L, Weinzimer S, et al. Feasibility of prolonged continuous glucose monitoring in toddlers with type 1 diabetes Pediatr Diabetes 2012;13:301-7.

24. Mauras N, Beck R, Xing D, et al. A randomized clinical trial to assess the efficacy and safety of real-time continuous glucose monitoring in the management of type 1 diabetes in young children aged 4 to $<10$ years. Diabetes Care 2012;35:204-10.

25. Williams RM, Dunger DB. Insulin treatment in children and adolescents. Acta Paediatr 2004;93:440-6.

26. Keith K, Nicholson D, Rogers D. Accuracy and precision of low-dose insulin administration using syringes, pen injectors, and a pump. Clin Pediatr (Phila) 2004;43:69-74. 
27. Bequette BW. A critical assessment of algorithms and challenges in the development of a closed-loop artificial pancreas. Diabetes Technol Ther 2005;7:28-47.

28. Service FJ, Molnar GD, Rosevear JW, et al. Mean amplitude of glycemic excursions, a measure of diabetic instability. Diabetes 1970;19:644-55.

29. Kovatchev BP, Cox DJ, Gonder-Frederick LA, et al. Assessment of risk for severe hypoglycemia among adults with IDDM: validation of the low blood glucose index. Diabetes Care 1998;21:1870-5.

30. Clarke WL. The original Clarke Error Grid Analysis (EGA). Diabetes Technol Ther 2005;7:776-9.

31. Hovorka R, Elleri D, Thabit $\mathrm{H}$, et al. Overnight closed-loop insulin delivery in young people with type 1 diabetes: a free-living, randomized clinical trial. Diabetes Care 2014;37:1204-11.

32. Elleri D, Allen JM, Nodale M, et al. Automated overnight closed-loop glucose control in young children with type 1 diabetes. Diabetes Technol Ther 2011;13:419-24.

33. Elleri $\mathrm{D}$, Allen JM, Biagioni $\mathrm{M}$, et al. Evaluation of a portable ambulatory prototype for automated overnight closed-loop insulin delivery in young people with type 1 diabetes. Pediatr Diabetes 2012;13:449-53.
34. Nabhan ZM, Kreher NC, Greene DM, et al. A randomized prospective study of insulin pump vs. insulin injection therapy in very young children with type 1 diabetes: 12-month glycemic, $\mathrm{BMI}$, and neurocognitive outcomes. Pediatr Diabetes 2009;10:202-8.

35. Hovorka R, Nodale M, Haidar A, et al. Assessing performance of closed-loop insulin delivery systems by continuous glucose monitoring: drawbacks and way forward. Diabetes Technol Ther 2013;15:4-12.

36. Slover RH, Welsh JB, Criego A, et al. Effectiveness of sensor-augmented pump therapy in children and adolescents with type 1 diabetes in the STAR 3 study. Pediatr Diabetes 2012;13:6-11.

37. Ceriello A, Kilpatrick ES. Glycemic variability: both sides of the story. Diabetes Care 2013;36(Suppl 2):S272-5.

38. Sundberg F, Forsander G. Detection and treatment efficacy of hypoglycemic events in the everyday life of children younger than 7 years. Pediatr Diabetes 2014; 15:34-40. 